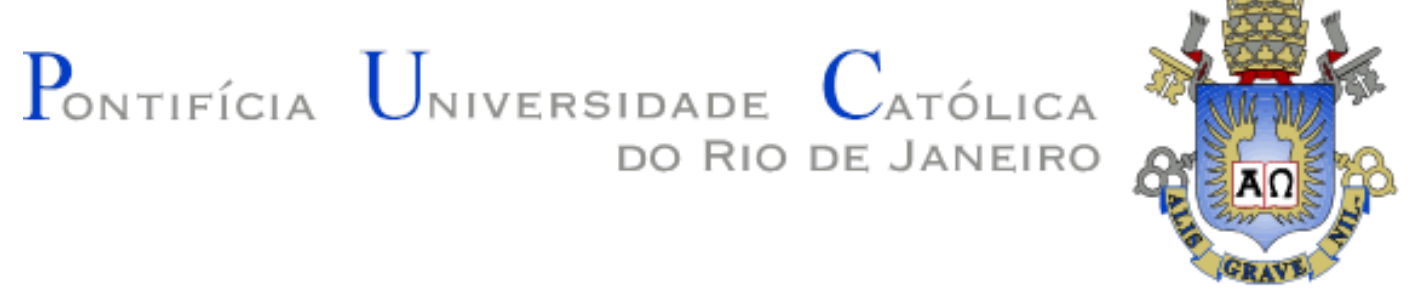

Marcela Racy Kurtenbach

\title{
ESTRUTURA DEMOGRÁFICA E A TRANSMISSÃO DA POLÍTICA MONETÁRIA
}

Dissertação De Mestrado

Dissertação apresentada ao Programa de Pós-Graduação em Macroeconomia e Finanças do Departamento de Economia, PUC-Rio como requisito parcial para obtenção do grau de Mestre em Macroeconomia e Finanças.

Orientador: Prof. Tiago Couto Berriel 
GRAVI

Marcela Racy Kurtenbach

\section{ESTRUTURA DEMOGRÁFICA E A TRANSMISSÃO DA POLÍTICA MONETÁRIA}

Dissertação apresentada como requisito parcial para obtenção do grau de Mestre pelo Programa de Pós-Graduação em Macroeconomia e Finanças da PUC-Rio. Aprovada pela Comissão Examinadora abaixo assinada.

Prof. Tiago Couto Berriel Orientador Departamento de Economia - PUC-Rio

Prof. Eduardo Zilberman Departamento de Economia - Puc-Rio

Prof. Rafael Chaves Santos Departamento de Economia - FGV/EPGE

Prof. Augusto Cesar Pinheiro da Silva Vice-Decano Setorial de Pós Graduação do Centro de Ciências Sociais -PUC-Rio

Rio de Janeiro, 18 de Agosto de 2017 
Todos os direitos reservados. É proibida a reprodução total ou parcial do trabalho sem autorização da universidade, da autora e do orientador.

\section{Marcela Racy Kurtenbach}

Graduada em Economia pela PUC-Rio em 2013.

Ficha Catalográfica

Kurtenbach, Marcela Racy

Estrutura demográfica e a transmissão da política monetária / Marcela Racy Kurtenbach ; orientador: Tiago Couto Berriel. - 2017.

35 f. : il. color. ; $30 \mathrm{~cm}$

Dissertação (mestrado)-Pontifícia Universidade Católica do Rio de Janeiro, Departamento de Economia, 2017.

Inclui bibliografia

1. Economia - Teses. 2. Estrutura etária. 3. Envelhecimento da população. 4. Eficácia da política monetária. I. Berriel, Tiago Couto. II. Pontifícia Universidade Católica do Rio de Janeiro. Departamento de Economia. III. Título.

CDD: 330 


\section{Agradecimentos}

Ao meu Orientador, Tiago Berriel, pelo estímulo, aprendizado e confiança durante o mestrado. Sua contribuição foi fundamental para este trabalho e formação.

Ao Eduardo Zilberman e Rafael Chaves, que ajudaram a sofisticar esse trabalho com sugestões e contribuições.

Aos Professores do Departamento de Economia da PUC-Rio pelos excelentes cursos ministrados, que fazem parte da minha formação desde a graduação.

Ao meu namorado, Pedro Abinader. Sem o apoio e carinho dele essa conquista não seria possível.

À minha família e às minhas amigas, que independente de qualquer coisa, estão sempre ao meu lado e por todo apoio durante esta jornada. Em especial, gostaria de agradecer à Marcella Derze, que foi essencial para a realização deste curso. O mestrado me deu mais do que um título, e sim uma amizade que agora faz parte da minha vida. 


\section{Resumo}

Racy Kurtenbach, Marcela; Couto Berriel, Tiago (Orientador). Estrutura Demográfica e a Transmissão da Política Monetária. Rio de Janeiro, 2017, 35p. Dissertação de Mestrado - Departamento de Economia, Pontifícia Universidade Católica do Rio de Janeiro.

Neste estudo iremos empiricamente avaliar o impacto do envelhecimento da população na eficácia da política monetária. Primeiramente, estimaremos o impacto da política monetária sobre o hiato do produto e inflação, evidenciando um enfraquecimento geral da transmissão da política monetária ao longo do tempo. Em outras palavras, hiato do produto e inflação menos sensíveis às mudanças nas taxas de juros. Depois, utilizaremos o método de OLS para testar o efeito negativo e estatisticamente significativo das alterações demográficas na eficácia da política monetária.

\section{Palavras-chave}

Estrutura etária; envelhecimento da população; eficácia da política monetária. 


\section{Abstract}

Racy Kurtenbach, Marcela; Couto Berriel, Tiago (Advisor). Demographic Structure and the Transmission of Monetary Policy. Rio de Janeiro, 2017, 35p. Dissertação de Mestrado - Departamento de Economia, Pontifícia Universidade Católica do Rio de Janeiro.

In this study we will empirically evaluate the impact of population aging on the effectiveness of monetary policy. First, we will estimate the impact of monetary policy on the output gap and inflation, evidencing a general weakening of monetary policy transmission over time. In other words, output gap and inflation are less sensitive to changes in interest rates. Then we will use the OLS method to test the negative and statistically significant effect of demographic changes on the effectiveness of monetary policy.

\section{Keywords}

Age structure; population aging; monetary policy effectiveness. 


\section{Sumário}

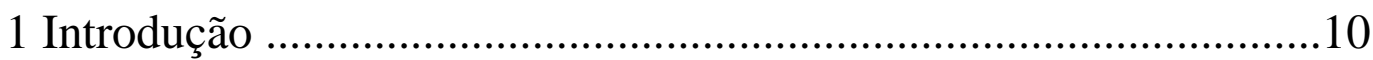

2 Mecanismos de Transmissão da Política Monetária 13

3 Modelos Empíricos .20

3.1 Modelo VAR e Impacto Variável no Tempo da Política

Monetária 21

3.2 Modelo de Regressão: A Transição Demográfico Explica o

Enfraquecimento da Eficácia da Política Monetária? 24

4 Conclusão e Implicações Políticas 28

5 Referências bibliográficas .31

Apêndice 1 32

Apêndice 2 .32 


\section{Lista de figuras}

Figura 1: Taxa de Fecundidade: Atual e Projetado por Região (1950 até 2100) .. 14

Figura 2: Expectativa de Vida ao Nascer: Atual e Projetado por região (1950

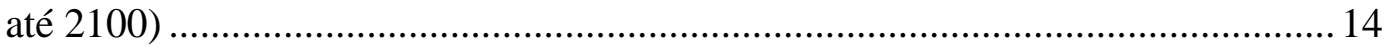

Figura 3: Razão de Dependência (>64 anos): Atual e Projetado por Região

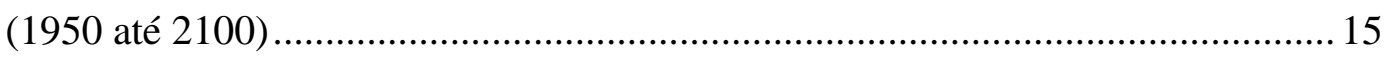

Figura 4: Transição Demográfica Brasil 1950-2100: Taxa de Natalidade, Taxa de Mortalidade e Crescimento Populacional ................................................. 15

Figura 5: Função resposta-impulso: Máxima e Acumulada para o Brasil (1995 até 2016)

Figura 6: Função resposta-impulso: Máxima e Acumulada para o Canada (1967 até 2016) 33

Figura 7: Função resposta-impulso: Máxima e Acumulada para os Estados Unidos (1967 até 2016)

Figura 8: Função resposta-impulso: Máxima e Acumulada para o Japão (1979 até 2016) 34

Figura 9: Função resposta-impulso: Máxima e Acumulada para o México (1990 até 2016) 34

Figura 10: Função resposta-impulso: Máxima e Acumulada para o Chile (1995 até 2016) 


\section{Lista de Tabelas}

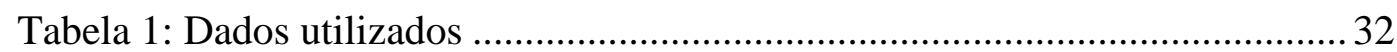

Tabela 2: Resultado da estimação das regressões para Canada, Estados

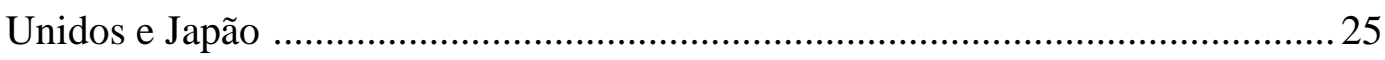

Tabela 3: Estimação da regressão para toda nossa amostra de países .................. 26

Tabela 4: Estimação da regressão com efeito fixo para países desenvolvidos ......... 27

Tabela 5: Estimação da regressão com efeito fixo para toda nossa amostra

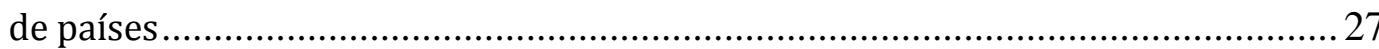




\section{Introdução}

Em um mundo em que a população seja mais velha, a maneira como a política monetária é conduzida precisa ser diferente? Esta é a questão que procuramos investigar.

As mudanças de política monetária têm efeitos diferentes sobre várias faixas etárias e, portanto, sobre se a eficácia da política monetária muda com envelhecimento da população.

Vamos neste estudo buscar uma explicação adicional. O impacto econômico e político do envelhecimento da população tem sido amplamente estudado no contexto da política físcal, especialmente no que diz respeito às suas implicações no sistema de seguridade social. A literatura, entretanto, manteve por muito tempo, de modo geral, os estudos de política monetária e demográfica separados, tratando efetivamente estes como questões independentes.

Vamos argumentar que a demografia deve ter uma influência importante na eficácia e, portanto, na condução da política monetária. Mais especificamente que os efeitos da política monetária sobre a economia enfraquecem com a evolução demográfica.

Esta é uma questão relevante porque a população no mundo será, em média, substancialmente mais velha no futuro. Por exemplo, na Europa, é provável que a proporção da população com mais de 65 anos seja de cerca de 50\% maior em 30 anos. E este resultado tem implicações significativas para condução da política monetária. Por exemplo, para obter o mesmo impacto sobre a atividade e a inflação, ceteris paribus, as mudanças nas taxas de juros terão de se tornar maiores em populações mais velhas, do que nas mais jovens.

Os perfis demográficos mudam significativamente de país para país. Enquanto alguns países envelhecem mais rapidamente do que outros (como, Alemanha e Japão), nenhuma parte do mundo permanece intocada por esse fenômeno. Com as taxas de fertilidade despencando em todo o mundo, inclusive em países de baixa 
renda, o mundo está passando por uma mudança demográfica sem precedentes e que está levando a um mundo rapidamente envelhecido. Os idosos costumavam representar uma pequena parcela da população, mas avanços tecnológicos e mudanças sociais nos últimos dois séculos transformaram essa estrutura demográfica.

Conceitualmente, numa país em envelhecimento, esperaríamos a priori que os vários canais através dos quais funciona o mecanismo de transmissão monetária variassem, alguns se tornando mais fortes, outros mais fracos. Os cortes mais novos e mais velhos são afetados de forma diferente, afetando a eficácia da política monetária em geral. De acordo com a teoria do ciclo de vida (Modigliani, 1970), as pessoas poupam nas fases iniciais da vida para suavizar o consumo ao longo do ciclo de vida e ter dinheiro para manter o padrão de vida na aposentadoria. Dessa forma, os padrões de poupança e consumo seguem uma trajetória bem definida, que muda à medida que a população envelhece, com níveis de dívida subindo e depois caindo ao longo do ciclo de vida. Apesar de simples, essa ideia resulta em diversos desdobramentos não triviais, como a explicação das taxas de poupança e como variam de acordo com variáveis demográficas e econômicas.

Dessa forma, é esperado que populações mais velhas, tipicamente com um grande percentual de credores, sejam menos sensíveis às alterações das taxas de juros; enquanto que populações mais jovens, que normalmente tem um maior percentual de devedores, tenham sensibilidades mais elevadas à política monetária. Assim, as sociedades dominadas por famílias mais velhas tendem a ser menos sensíveis às mudanças nas taxas de juros, tudo o mais constante, e logo, as mudanças na política monetária seriam menos efetivas.

Iremos empiricamente avaliar o impacto do envelhecimento na eficácia da política monetária. Primeiramente, iremos estimar o impacto da política monetária sobre o hiato do produto e inflação, evidenciando um enfraquecimento geral da transmissão da política monetária ao longo do tempo. Em outras palavras, atividade e inflação menos sensíveis às mudanças nas taxas de juros. Depois, utilizaremos o método de OLS para testar o efeito negativo e estatisticamente significativo das alterações demográficas na eficácia da política monetária. 
Este estudo será estruturado da seguinte forma. No capítulo 2, analisaremos quadro demográfico global atual e projetado, seguida de uma explicação dos vários canais através dos quais as mudanças demográficas podem levar a mudanças na eficácia da política monetária. No capítulo 3, usando um modelo VAR, estimaremos o impacto da eficácia da política monetária ao longo do tempo. Usando funções de resposta de impulso, analisaremos se existe um enfraquecimento geral do impacto da política monetária sobre atividade e inflação, sugerindo uma diminuição da eficácia ao longo do tempo. Em seguida, testaremos a relação entre mudanças demográficas e enfraquecimento da política monetária. Concluiremos no capítulo 4 e discutimos as implicações políticas.

Os resultados sugerem que os formuladores de políticas devem levar em conta o perfil demográfico do país na condução de políticas monetárias. Em particular, a política monetária terá de operar de forma diferente e mais agressiva nos países mais velhos para obter o mesmo impacto que numa sociedade mais jovem.

A política monetária é um instrumento chave dos formuladores de políticas para estabilizar a economia. Se o envelhecimento da população reduz marginalmente a eficácia da política monetária, outros instrumentos para estabilizar a economia tornam-se necessários. O papel relativo da política fiscal e macro prudencial como um meio para estabilizar a economia pode se tornar cada vez mais importante. 


\section{Mecanismos de Transmissão da Política Monetária}

O envelhecimento da população, como consequência de um aumento significativo da expectativa de vida e da baixa fertilidade, é um fenômeno mundial. Como consequência, vemos um aumento da proporção de pessoas idosas e uma proporção cada vez menor de crianças/jovens. O corte de idosos (65+) e muito idosos (80+) está crescendo muito mais rápido do que os jovens, e com a população de idosos também envelhecendo.

Estas são tendências de longo prazo e mudanças demográficas demoram até se concretizarem através da estrutura etária. Entretanto, vale destacar que nos países desenvolvidos, o envelhecimento da população já ocorreu significativamente, e que tal processo está ocorrendo rapidamente, apesar de mais recentemente, em países em desenvolvimento.

De acordo com as projeções das Nações Unidas (revisão de 2015), a expectativa de vida global ao nascer aumentou significativamente de 64,5 anos em 1995 para 70,5 anos em 2015 e a taxa de fertilidade total (número médio de nascimentos por mulher) diminuiu significativamente de 3,04 para 2,47 crianças durante o mesmo período.

De acordo com esta tendência crescente de longevidade e decrescente de fecundidade, em 2015, 12\% da população global ou 901 milhões de pessoas tinha idade igual ou superior a 60 anos, e essa participação deverá aumentar para $22 \%$ até 2050 . 
Figuras 1, 2 e 3: Taxa de Fecundidade, Expectativa de Vida ao Nascer e Razão de Dependência (>64 anos): Atual e Projetado por Região (1950 até 2100)
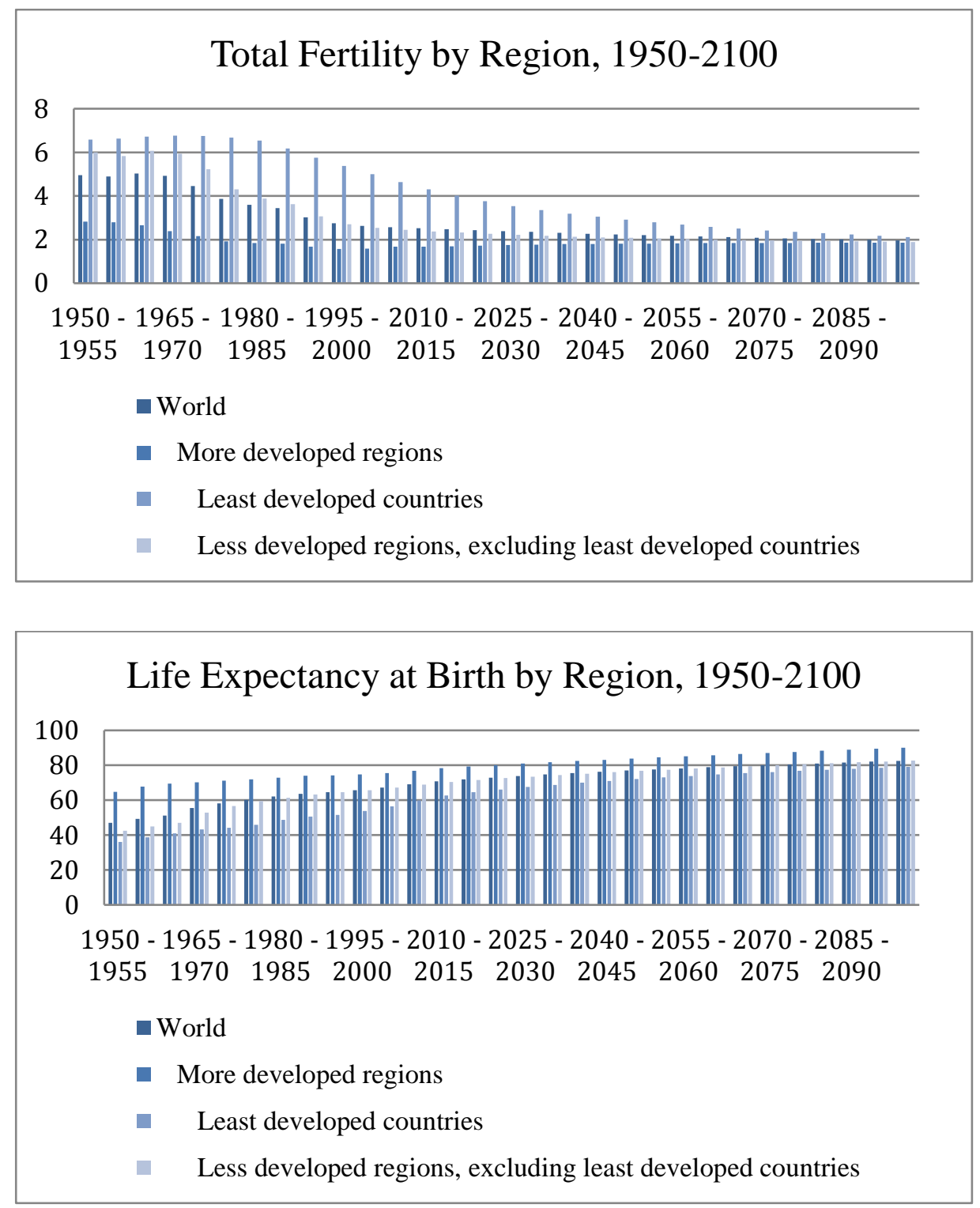


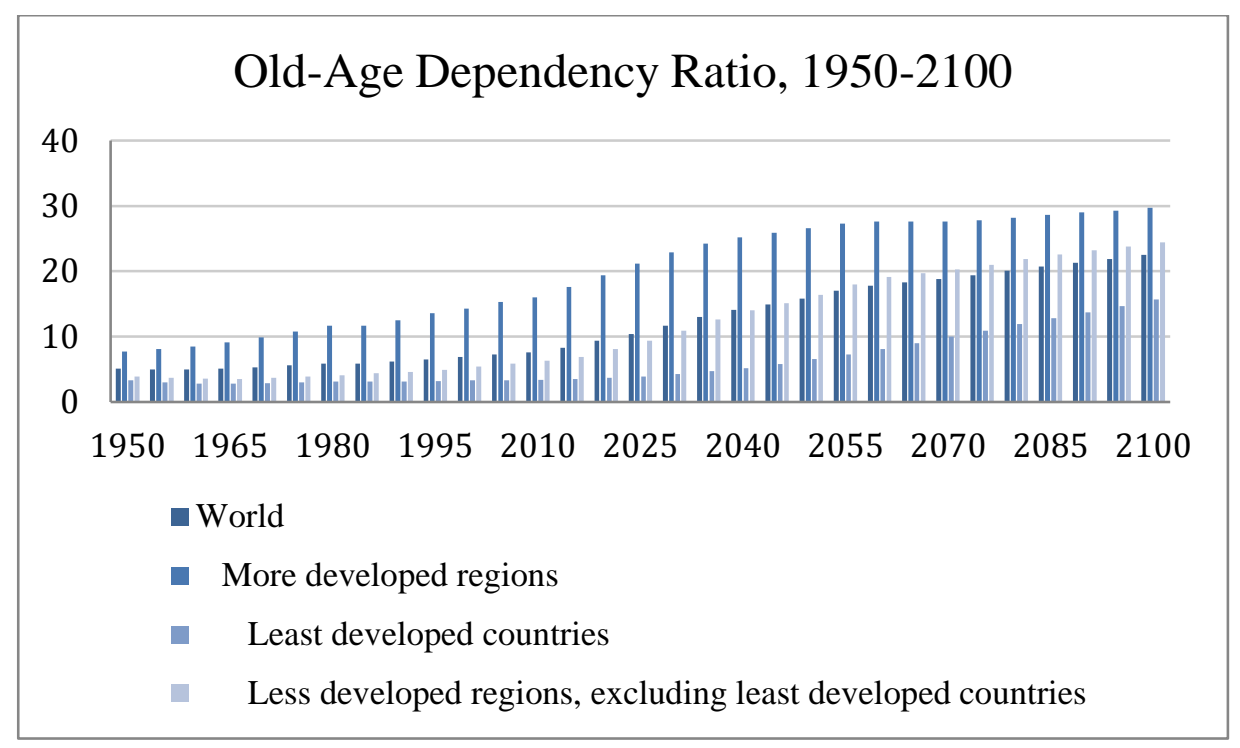

Fonte: ONU - http://esa.un.org/wpp/unpp/panel_indicators.htm

Vamos a seguir analisar especificamente os dados do Brasil.

O gráfico abaixo mostra o processo de transição demográfica do Brasil de 1950 até 2100. Foram utilizados os dados e as projeções das Nações Unidas (revisão de 2015). Nota-se que nos próximos anos as taxas brutas de mortalidade vão ficar praticamente estáveis, enquanto as taxas brutas de natalidade vão continuar caindo, o que vai reduzir o ritmo de crescimento da população.

\section{Figura 4: Transição Demográfica Brasil 1950-2100: Taxa de Natalidade, Taxa de Mortalidade e Crescimento Populacional}

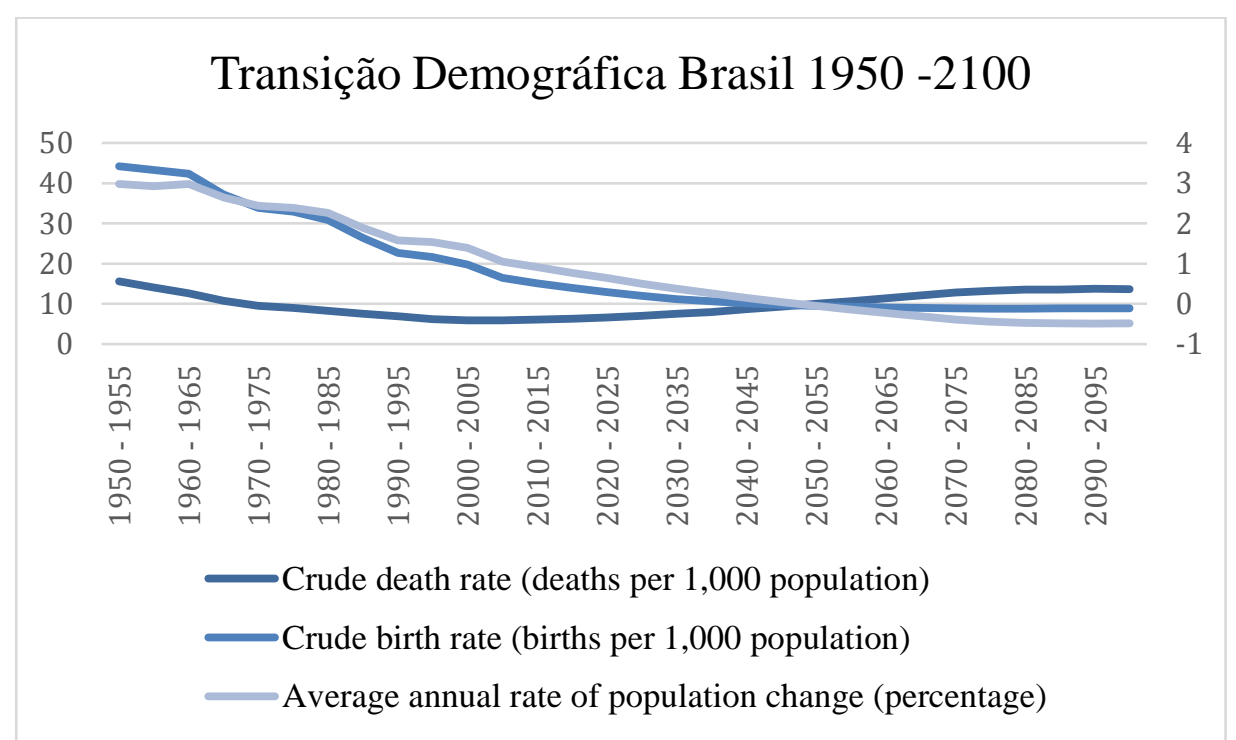

Fonte: ONU - http://esa.un.org/wpp/unpp/panel_indicators.htm 
Para o Brasil, a expectativa de vida ao nascer aumentou de 66,4 anos em 1995 para 74 anos em 2015 e a taxa de fertilidade seguiu trajetória descendente e se estabilizou em aproximadamente dois filhos por criança após 2010.

Além disso, em 1950, cerca de 140 crianças morriam por ano antes de completar um ano de vida. A mortalidade infantil caiu para aproximadamente 30 por mil em 2000 e deve ficar abaixo de 10 a partir de 2030.

Em 2015, 7,8\% da população brasileira tinha idade igual ou superior a 65 anos, e essa proporção deverá aumentar para 22,8\% até 2050.

Neste estudo, iremos expandir a segunda vertente da literatura sobre a influência do envelhecimento populacional nas economias e investigaremos especificamente a relação entre a estrutura demográfica e a eficácia da política monetária. É importante ressaltar que, embora a eficácia da política monetária tenha atraído a atenção de economistas e de formuladores de políticas, a pesquisa empírica que avalia a influência da estrutura demográfica (ou o envelhecimento da população em particular) sobre a eficácia da política monetária é muito limitada na literatura.

Estudos sobre o mecanismo monetário subjacente à influência do envelhecimento da população foram influenciados pela Hipótese do Ciclo de Vida de consumo e poupança. Esta hipótese argumenta que pessoas em idade ativa poupam para sua aposentadoria, enquanto crianças e idosos tendem a consumir mais do que produzem. Uma mudança significativamente desproporcional na estrutura demográfica resultaria num desequilíbrio entre poupança (ao longo da vida) e investimento que, por sua vez, provocaria alguns ajustes nos vários canais através do qual o mecanismo de transmissão monetária funciona.

Iremos destacar os principais deles.

\section{Canal da Taxa de Juros}

De acordo com a hipótese do ciclo de vida, os indivíduos adquirem ativos, primeira moradia e, em seguida, ativos financeiros, ao longo do seu período economicamente ativo, e os vendem quando se aposentam. Tanto o padrão de poupança e padrão de consumo das famílias seguem, portanto, uma trajetória bem 
estabelecida que muda com envelhecimento; com níveis de endividamento subindo e posteriormente, caindo durante o ciclo de vida. Nessas circunstâncias, esperamos que os jovens, que normalmente são devedores, sejam mais sensíveis às mudanças nas taxas de juros enquanto que os mais velhos, que normalmente são credores, sejam menos sensíveis a este canal.

Assim, os países de maioria da população mais velha tendem a ser menos sensíveis às mudanças nas taxas de juros, tudo o mais constante, e mudanças na política monetária seriam menos eficazes, dada a importância de suavizar o consumo durante o ciclo de vida.

\section{Canal de Crédito}

Este canal amplifica o canal de taxa de juros ao afetar o canal de financiamento externo, que é a diferença entre o custo de capital disponível para famílias/empresas versus o custo do endividamento externo.

O canal de crédito pressupõe que o montante do prêmio de financiamento externo é inversamente proporcional ao patrimônio líquido do mutuário. Numa sociedade em envelhecimento com famílias com maior patrimônio líquido, dado seu alto valor de colateral, o prêmio de risco dos empréstimos é menor e, por conseguinte, o custo de contrair um empréstimo externo é menor. Isso implica em uma menor sensibilidade à política monetária no canal de crédito em sociedades de envelhecimento.

\section{Canal de Aversão a Risco}

A política monetária afeta a percepção de risco dos agentes econômicos. Em um país em envelhecimento, o tempo para recuperar perdas é menor do que em sociedade mais jovem, o que pode levar a famílias mais avessas ao risco e, portanto, menor seja a tomada de risco, reduzindo assim a eficácia da política monetária.

\section{Canal das Expectativas}

O canal de expectativa não deveria ser afetado com mudança demográfica, uma vez que está condicionada à credibilidade do banco central. Entretanto, estudos recentes, sugerem que idosos tendem a ter maior aversão ao risco à inflação, devido ao maior impacto que inflação teria para eles dado sua posição de credor. 
Na prática, isto implicaria que, em países em envelhecimento, o banco central deveria agir mais agressivamente para combater a inflação.

Dessa forma, como podemos observar, a mudança demográfica tem impactos relevantes nas respostas de uma economia à mudança da política monetária. Mais especificamente, a política monetária pode tornar-se menos potente numa sociedade em transição demográfica.

Devemos destacar também o canal Efeito Renda, agindo no sentido oposto dos demais canais descritos acima.

Os indivíduos jovens normalmente possuem poucos ativos, enquanto os mais velhos possuem muitos. Para uma família que já adquiriu ativos substanciais ao longo da vida, o impacto das mudanças na taxa de juros em sua renda é maior do que se comparado a uma família com poucos recursos.

Em sociedades em envelhecimento, os efeitos renda ganhariam importância cada vez maior, uma vez que a riqueza tende a se concentrar entre os idosos (pelo menos nos países da OCDE).

Argumentamos que uma mudança para uma estrutura demográfica em que os idosos representam uma fração crescente da população deverá produzir uma mudança gradual, mas persistente, nos hábitos de poupança. Isso teria um impacto na demanda por todas as classes de ativos, embora certos segmentos do mercado de capitais provavelmente sejam afetados mais substancialmente do que outros.

Como as pessoas mais idosas são mais avessas ao risco e preferem manter ativos financeiros que paguem retornos de renda fixa, a demanda por títulos do governo tenderia a aumentar em relação às opções de investimento mais arriscadas, o que acentua a sensibilidade às mudanças de taxa de juros decorrentes do canal de efeito de renda.

A mudança demográfica, portanto, tenderia a aumentar a importância relativa do canal de efeito renda, aumentando a eficácia da política monetária.

No caso do Brasil, a partir dos critérios e dados mostrados acima, podemos concluir que o país se encontrava na última fase de sua transição demográfica no final da década de 1990, com números para saúde e fecundidade semelhantes aos 
da faixa média de outros países em desenvolvimento. Nas estimativas a seguir, buscaremos encontrar potencial enfraquecimento da transmissão da política monetária ao longo do tempo. Vale ressaltar que o foco será na estimativa do efeito agregado, e não explicitamente nos efeitos de cada individualmente. 


\section{Modelos Empíricos}

O objetivo principal deste estudo é avaliar o efeito da mudança demográfica na eficácia da política monetária na nossa amostra de seis países: Brasil, Canada, Chile, Estados Unidos, Japão e México.

Como o envelhecimento da população é um fenômeno suave e de longo prazo, não é fácil de estimar a resposta de uma economia a essas mudanças.

Para resolver esse problema, seguiremos a abordagem utilizada em Iman Patrick (2013) e utilizaremos coeficientes variáveis no tempo para a amostra completa usando modelos de vetores auto regressivos (VARs), que tem pressupostos menos restritivos sobre o comportamento da economia.

Usaremos as respostas da inflação e do hiato do produto para uma mudança de taxa de juros como uma medida de eficácia da política monetária, e em seguida iremos regredir esta medida de eficácia da política monetária em uma única medida demográfica (ou seja, na razão de dependência da população acima de 64 anos) para identificar a relação entre envelhecimento da população e eficácia da política monetária.

Para os nossos seis países, os dados foram obtidos principalmente em uma periodicidade anual dos bancos centrais dos países e da base de dados do banco mundial (ver apêndice 1). 


\section{1}

\section{Modelo VAR e Impacto Variável no Tempo da Política Monetária}

As respostas impulso-hiato do produto e inflação a uma mudança de taxa de juros foram estimadas pelo modelo VAR na variável $Y_{t}=\left[y_{t}, \pi_{t}, i_{t}\right]$ definido pela equação abaixo.

$$
Y_{t}=c_{t}+B_{1, t} Y_{t-1}+B_{2, t} Y_{t-2}+\cdots+B_{p, t} Y_{t-p}+\varepsilon_{t}
$$

Neste modelo, $y_{t}$ corresponde produto, $\pi_{t}$ a inflação, $i_{t}$ a taxa de juros, $B_{1, t}$, $B_{2, t}, \ldots, B_{p, t}$ são matrizes $3 \times 3$ de parâmetros variáveis no tempo e $\varepsilon_{t}$ um vetor $3 \times 1$ de choques heteroscedásticos com matriz de covariância $\Omega$.

É importante abordar que os estudos empíricos que utilizam medidas de PIB e taxas de juros nominais durante um longo período de tempo devem lidar com o fato de que essas variáveis provavelmente são séries temporais não estacionárias, tornando inválida a maioria das inferências estatísticas.

Para lidar com esse problema, utilizaremos o hiato do produto para medida de atividade e o hiato da taxa de juros para substituir a taxa de juros nominal. Essas variáveis foram calculadas pela diferença logarítmica da série original pela tendência de longo prazo construída pelo método de filtro Hodrick-Prescott.

A inflação é definida como a primeira diferença do índice de preços ao consumidor.

Realizamos o teste de raiz unitária ADF para todas as variáveis utilizadas no modelo e como esperávamos, são séries temporais estacionárias. Logo, o modelo VAR utilizando primeira diferença da taxa de inflação, hiato da taxa de juros e hiato do produto, evita inferências estatísticas inválidas e é adequado para gerar as respostas da inflação e do produto a mudanças na taxa de juros.

O choque da política monetária é identificado através da decomposição de Choleski com as variáveis ordenadas conforme $Y_{t}=\left[y_{t}, \pi_{t}, i_{t}\right]$. Esta decomposição é padrão na literatura VAR, permitindo tanto coeficientes que variam no tempo quanto volatilidade estocástica. 
O pressuposto subjacente é que os choques de política monetária não apresentam um impacto contemporâneo no hiato do produto e nem na inflação.

Se impusermos identificação recursiva na equação (1), $\Omega$ pode ser decomposto em $\Omega=A_{t}^{-1} \sum_{t} \sum_{t} A_{t}^{\prime-1}$ onde $A_{t}$ é uma matriz de triangular inferior com os elementos diagonais iguais a um e $\sum_{t}=\operatorname{diag}\left(\sigma_{1 t}, \sigma_{2 t}, \sigma_{3 t}\right)$.

$$
A_{t}=\begin{array}{ccc}
1 & 0 & 0 \\
\phi_{1 t} & 1 & 0 \\
\phi_{2 t} & \phi_{3 t} & 1
\end{array} ; \Sigma_{t}=\begin{array}{ccc}
\sigma_{1 t} & 0 & 0 \\
0 & \sigma_{2 t} & 0 \\
0 & 0 & \sigma_{3 t}
\end{array}
$$

A dinâmica dos parâmetros do modelo $\phi_{t}=\left[\phi_{1 t}, \phi_{2 t}, \phi_{3 t}\right]$ e $\log \left(\sigma_{t}\right)=$ $\left[\sigma_{1 t}, \sigma_{2 t}, \sigma_{3 t}\right]$ é suposta a seguir passeio aleatório. Assumindo que os componentes diagonais devem seguir um passeio aleatório implica que o modelo pertence à classe de VARs usando volatilidade estocástica para capturar a heterocedasticidade nos erros.

As suposições de passeio aleatório são convenientes, uma vez que reduzem simultaneamente o número de parâmetros na estimação enquanto que ainda permitem que os parâmetros apresentem desvios permanentes.

Estimamos o modelo VAR usando janelas móveis. A principal vantagem dessa abordagem é em lidar com a alta dimensionalidade e não-linearidade do problema.

Os resultados encontrados levam a valores principalmente negativos tanto nas respostas acumuladas quanto nas respostas máximas do hiato e da inflação após um choque positivo na taxa de juros.

No apêndice 2 encontram-se as funções de resposta impulso para o mecanismo de propagação de um choque não antecipado da taxa de juros sobre hiato do produto e inflação ao longo período analisado na nossa amostra de países.

O hiato do produto geralmente diminui para todos os países durante os primeiros períodos após o choque da política monetária. Além disso, os choques de política monetária também tiveram um impacto decrescente ao longo do tempo sobre a inflação. 
É importante notar que enquanto os países emergentes e os países de baixa renda, também envelhecerão gradualmente, o impacto observado ao longo do tempo é menor do que nas economias avançadas, as primeiras a passar pela mudança demográfica.

Isso acontece, pois, os países emergentes e de mais baixa renda, estão em uma situação peculiar, uma vez que passarão por uma transição demográfica sem terem se tornado ricos. Como as pessoas idosas são muitas vezes pobres nesses países e sustentados por membros em idade ativa da família, alguns dos fatores discutidos serão menos importantes, o que implica que a eficácia da política monetária pode não enfraquecer tanto quanto nos países desenvolvidos, ou se manifestar através de outros canais.

No caso particular do Brasil, ainda devemos ressaltar a existência de um dos sistemas de previdência mais benevolentes do mundo, que reduz os incentivos para poupança, e logo também explica o menor impacto sobre hiato e inflação.

Em suma, embora existam diferenças notáveis entre países, nossas estimativas indicam mudanças na eficácia da política monetária ao longo do tempo. Em particular, nossas estimativas implicam que as mudanças nas taxas de juros em nossa amostra de países têm menos impacto sobre a inflação e o desemprego hoje do que no passado. Isso poderia potencialmente explicar em parte as perdas significativas de PIB que ocorreram na recessão recente, apesar das grandes quedas nas taxas de juros. 


\section{Modelo de Regressão: A Transição Demográfico Explica o Enfraquecimento da Eficácia da Política Monetária?}

Na seção anterior, observamos um declínio notável na eficácia da política monetária no período observado para a nossa amostra de países. Nesta seção, tentaremos explicar o que contribuiu para esse declínio. Em particular, iremos focar no impacto potencial do envelhecimento - medido pela razão de dependência dos idosos - como explicação para a queda da eficácia da política monetária.

As respostas da inflação e do hiato do produto à variação da taxa de juros foram utilizadas para criar medidas de eficácia da política monetária, que são respostas acumuladas e respostas máximas após um choque de um desvio padrão nos juros. Essas duas medidas serviram de variáveis dependentes no modelo a seguir. Além disso, obtivemos dados da razão de dependência da população acima de 64 anos e estimamos a seguinte regressão para a nossa amostra de países.

$$
\begin{gathered}
i m p_{i t}^{j}=\beta_{i 1}+\beta_{2} \text { oldage }_{i t}+e_{i t} \\
j=y, \pi
\end{gathered}
$$

Onde $i m p_{i t}^{j}$ denota impacto da política monetária na variável j no período $\mathrm{t}$ no país i e oldage $e_{i t}$ denota a medida demográfica do país i.

A teoria macroeconômica convencional prevê que, tudo o mais constante, a política monetária contracionista, em termos de aumento de taxa de juros, leva a uma inflação menor e um produto também menor. Portanto, valores positivos de $i m p^{\pi}$ e $i m p^{y}$ sugerem que a política monetária é menos eficaz em relação à inflação e ao hiato do produto.

As regressões estimadas estão apresentadas na tabela a seguir. Nas equações (1) e (2), a variável dependente é o impacto da política monetária sobre o hiato do produto, enquanto nas equações (3) e (4), referem-se à inflação.

Inicialmente, estimamos as regressões apenas para as economias avançadas: Canada, Estados Unidos e Japão. 


\begin{tabular}{|c|ccc|ccc|}
\hline \multirow{2}{*}{ Variável } & \multicolumn{3}{|c|}{ Hiato - Acumulado } & \multicolumn{3}{c|}{ Hiato - Máximo } \\
\cline { 2 - 7 } & Coeficiente & t valor & Prob. & Coeficiente & t valor & Prob. \\
\hline $\begin{array}{c}\text { Razão Dependência } \\
(>64 \text { anos) }\end{array}$ & 0.000317 & 2.14 & 0.0348 & 0.000185 & 2.94 & 0.0042 \\
\hline
\end{tabular}

\begin{tabular}{|c|ccc|ccc|}
\hline \multirow{2}{*}{ Variável } & \multicolumn{3}{|c|}{ Inflação - Acumulada } & \multicolumn{3}{c|}{ Inflação - Máxima } \\
\cline { 2 - 7 } & Coeficiente & t valor & Prob. & Coeficiente & t valor & Prob. \\
\hline $\begin{array}{c}\text { Razão Dependência } \\
\text { (>64 anos) }\end{array}$ & 0.000488 & 3.62 & 0.0005 & 0.000151 & 5.36 & 0.0000 \\
\hline
\end{tabular}

Os resultados revelam que uma sociedade em envelhecimento exerce impacto negativo (em termos absolutos) estatisticamente significativo no longo prazo sobre a eficácia da política monetária. Tudo o mais constante, um aumento na razão de dependência diminui (em termos absolutos) o impacto acumulado de um choque de política monetária no hiato do produto e na inflação em $0,03 \%$ e $0,05 \%$, respectivamente.

Em uma segunda etapa, estimamos as mesmas regressões para a nossa amostra de seis países, incluindo também os países em desenvolvimento. 
Tabela 3: Estimação da regressão para toda nossa amostra de países

\begin{tabular}{|c|ccc|ccc|}
\hline \multirow{2}{*}{ Variável } & \multicolumn{3}{|c|}{ Hiato - Acumulado } & \multicolumn{3}{c|}{ Hiato - Máximo } \\
\cline { 2 - 7 } & Coeficiente & t valor & Prob. & Coeficiente & t valor & Prob. \\
\hline $\begin{array}{c}\text { Razão Dependência } \\
\text { (>64 anos) }\end{array}$ & -0.000239 & -1.16 & 0.2466 & $-4.88 \mathrm{E}-05$ & -0.82 & 0.4117 \\
\hline
\end{tabular}

\begin{tabular}{|c|ccc|ccc|}
\hline \multirow{2}{*}{ Variável } & \multicolumn{3}{|c|}{ Inflação - Acumulada } & \multicolumn{3}{c|}{ Inflação - Máxima } \\
\cline { 2 - 7 } & Coeficiente & t valor & Prob. & Coeficiente & t valor & Prob. \\
\hline $\begin{array}{c}\text { Razão Dependência } \\
\text { (>64 anos) }\end{array}$ & 0.000493 & 2.71 & 0.0076 & 0.00032 & 3.74 & 0.0003 \\
\hline
\end{tabular}

O impacto correspondente de um choque de política monetária mostrou-se negativo e estatisticamente significativo apenas sobre a inflação. Ainda assim, isto é particularmente relevante quando ligado, por exemplo, ao aumento projetado de $8 \%$ para $11,5 \%$ no índice de dependência da velhice no Brasil durante a próxima década.

Nos resultados encontrados, a relação de longo prazo entre a redução da eficácia da política monetária e medidas demográficas podem ser estabelecida para ambas medidas de eficácia da política monetária (ou seja, respostas impulso acumuladas ou máximas) utilizadas em nossas análises.

Vamos repetir as estimativas acima, incluindo efeito fixo de tempo ou dummies de tempo, que capturam a influência das tendências agregadas nas séries temporais.

Este exercício é importante pois, em muitos casos, as variáveis em questão estão falsamente relacionadas simplesmente por causa da magnitude crescente das variáveis agregadas (devido ao crescimento econômico, crescimento populacional, inflação, etc). Nesse caso, regressões de dados em painel que não conseguem controlar para os efeitos fixos do tempo capturam a influência de tendências agregadas que não têm nada a ver com relações causais.

Os resultados encontrados seguem abaixo. 
Tabela 4: Estimação da regressão com efeito fixo para os países desenvolvidos

\begin{tabular}{|c|ccc|ccc|}
\hline \multirow{2}{*}{ Variável } & \multicolumn{3}{|c|}{ Hiato - Acumulado } & \multicolumn{3}{c|}{ Hiato - Máximo } \\
\cline { 2 - 7 } & Coeficiente & t valor & Prob. & Coeficiente & t valor & Prob. \\
\hline $\begin{array}{c}\text { Razão Dependência } \\
\text { (>64 anos) }\end{array}$ & 0.000416 & 2.16 & 0.0346 & 0.00037 & 4.31 & 0.0001 \\
\hline
\end{tabular}

\begin{tabular}{|c|ccc|ccc|}
\hline \multirow{2}{*}{ Variável } & \multicolumn{3}{|c|}{ Inflação - Acumulada } & \multicolumn{3}{c|}{ Inflação - Máxima } \\
\cline { 2 - 7 } & Coeficiente & t valor & Prob. & Coeficiente & t valor & Prob. \\
\hline $\begin{array}{c}\text { Razão Dependência } \\
\text { (>64 anos) }\end{array}$ & $-1.45 \mathrm{E}-05$ & -0.16 & 0.8716 & 0.000122 & 3.63 & 0.0006 \\
\hline
\end{tabular}

Tabela 5: Estimação da regressão com efeito fixo para toda nossa amostra de países

\begin{tabular}{|c|c|c|c|c|c|c|}
\hline \multirow{2}{*}{ Variável } & \multicolumn{3}{|c|}{ Hiato - Acumulado } & \multicolumn{3}{|c|}{ Hiato - Máximo } \\
\hline & Coeficiente & t valor & Prob. & Coeficiente & t valor & Prob. \\
\hline $\begin{array}{l}\text { Razão Dependência } \\
\text { (>64 anos) }\end{array}$ & -0.000153 & -0.73 & 0.4648 & $-1.52 \mathrm{E}-05$ & -0.24 & 0.8137 \\
\hline \multirow{2}{*}{ Variável } & \multicolumn{3}{|c|}{ Inflação - Acumulada } & \multicolumn{3}{|c|}{ Inflação - Máxima } \\
\hline & Coeficiente & t valor & Prob. & Coeficiente & t valor & Prob. \\
\hline $\begin{array}{l}\text { Razão Dependência } \\
\text { (>64 anos) }\end{array}$ & 0.000452 & 2.58 & 0.0111 & 0.000322 & 3.57 & 0.0006 \\
\hline
\end{tabular}

Com a inclusão de dummies de tempo, os impactos de um choque de política monetária sobre a inflação e sobre o hiato do produto se tornaram menos significativos. Ainda assim, é possível estabelecer a relação de longo prazo entre a redução da eficácia da política monetária e razão de dependência dos idosos. 


\section{Conclusão e Implicações Políticas}

Como argumentamos, existem várias maneiras pelas quais a mudança demográfica pode alterar a maneira como a política monetária deve ser conduzida.

Um dos principais pilares da teoria do ciclo de vida é que os indivíduos tentam suavizar o consumo ao longo da vida. Mudanças nas taxas de juros têm um impacto diferente no consumo e na poupança para pessoas de diferentes idades. Para os mais jovens, alteram o custo do consumo em diferentes pontos ao longo do ciclo de vida. Para os mais velhos, o maior impacto pode ser a mudança nos preços dos ativos induzida por uma mudança nas taxas de juros de curto prazo.

Para uma determinada idade de aposentadoria, o envelhecimento da população aumenta a proporção de famílias com uma taxa de poupança relativamente menor na economia e, portanto, tende a reduzir a poupança. Embora as estimativas do impacto de uma mudança na estrutura etária da população na poupança sejam tratadas com cautela, sua ordem de grandeza mostra claramente que o envelhecimento populacional tenderá a atenuar a poupança.

Por isso, uma mudança na estrutura demográfica de um país, provocaria um desequilíbrio entre poupança e investimentos que por sua vez, impactaria os mecanismos de transmissão da política monetária.

Ao mesmo tempo, um número crescente de aposentados dependeria mais de sua própria riqueza acumulada para sustentar seus níveis de consumo. Como resultado, a fração da população exposta às flutuações dos preços dos ativos pode aumentar com o envelhecimento.

Adicionalmente, o estoque de ativos financeiros detidos pelas famílias e a importância relativa desses ativos para o capital humano variam ao longo do ciclo de vida. Isso provavelmente significará que as restrições de crédito são mais importantes para os jovens do que para os idosos. Quanto mais pessoas estão no fim da sua vida profissional e na aposentadoria antecipada, e quanto menos jovens 
houver, então menos importantes são as restrições de crédito (ou liquidez). Isso também altera o impacto das mudanças nas taxas de juros sobre as despesas.

Neste estudo, analisamos que mudanças demográficas em economias com política monetária independente tem sido um fator contribuinte que explica a observada diminuição da eficácia da política monetária. Especificamente, nossos resultados empíricos demonstraram que a eficácia da política monetária é negativamente correlacionada com a proporção da população acima de 64 anos de idade.

Tais padrões de distribuição de idade, no nosso caso, levando a um envelhecimento da população e afetando as respostas de uma economia à mudança da política monetária são altamente consistentes com a previsão derivada da Hipótese do Ciclo de Vida de poupança e consumo.

Dessa forma, sociedades dominadas por famílias mais velhas tendem a ser menos sensíveis às mudanças de taxa de juros do que as sociedades mais jovens. A política monetária, portanto, tornar-se menos potente em uma sociedade passando por uma transição demográfica.

Os resultados sugerem que os formuladores de políticas devem levar em conta o quadro demográfico do país na condução da sua política monetária. Com uma tendência a favor do envelhecimento da população e por outro lado, uma tendência descendente nas taxas de juros mundial, a política monetária terá de ser mais agressiva nos países mais velhos (com uma maior variação nas taxas de juros) para obter o mesmo impacto que numa sociedade mais jovem.

Além disso, novos trade-offs podem surgir. A preferência relativa de estabilização da inflação versus atividade pode mudar. No ambiente em que os idosos representam uma fração crescente da população, uma fração maior da riqueza das famílias é investida em ativos nominais e, logo, a estabilidade de preços seria ainda mais importante para as famílias. Os preços estáveis garantem que o valor real dos direitos e poupanças seja mantido e evite redistribuições arbitrárias de renda e riqueza em detrimento dos grupos mais vulneráveis da sociedade, em particular dos pensionistas. 
É por isso que um compromisso crível para manter a estabilidade de preços e, como reflexão, um ambiente financeiro ordenado é e continuará a ser tão importante para manter o padrão de vida dos cidadãos. A crescente aversão à inflação pode, ceteris paribus, levar a uma meta menor para inflação ótima, enquanto que, por outro lado, as taxas de juros reais decrescentes, uma consequência importante do envelhecimento (por exemplo, Bean, 2004), provavelmente tem efeito oposto. Assim, os bancos centrais terão que pensar através desses trade-offs e ajustar suas políticas nessa direção.

Com a eficácia da política monetária marginalmente reduzida, outros instrumentos para estabilizar a economia tornam-se necessários. $\mathrm{O}$ papel relativo da política fiscal e macro prudencial como um meio para estabilizar a economia pode se tornar cada vez mais importante.

Também políticas que promovam a fertilidade ou a imigração através de incentivos fortes para ter mais filhos e atrair trabalhadores mais jovens e mais qualificados devem estar no radar das agendas de políticas econômicas e populacionais para aliviar os impactos negativos do rápido envelhecimento populacional na economia no futuro próximo.

Por fim, devemos destacar os efeitos encontrados menos significantes da queda da eficácia da política monetária no contexto de baixa renda. Países em desenvolvimento, como Brasil e México, passarão pela transição demográfica e pelo consequente, envelhecimento da população, sem terem se tornado ricos. Dessa maneira, alguns dos canais discutidos serão menos importantes, o que implica que a eficácia da política monetária pode não enfraquecer tanto quanto nos países desenvolvidos. 


\section{Referências bibliográficas}

1 Bean, Charles, 2004, Global Demographic Change: Some Implications for Central Banks, (Federal Reserve Bank of Kansas City Annual Symposium, Jackson Hole, Wyoming).

2 Bloom, David, David Canning and Günther Fink, 2010, Implications of population ageing for economic growth, Oxford Review of Economic Policy, Oxford Review of Economic Policy, Vol. 26, pp. 583-612.

3 Boivin, Jean, Michael Kiley and Frederic Mishkin, 2010, How Has the Monetary Transmission Mechanism Evolved Over Time? NBER Working Paper No. 15879.

4 Charalambos Tsangarides, 2010, Monetary Policy Transmission in Mauritius Using a VAR Analysis IMF Working Paper No. 1036.

5 Fijuwara, Ippei and Yuki Teranishi, 2008, A dynamic new Keynesian lifecycle model: Societal aging, demographics, and monetary policy, Journal of Economic Dynamics and Control, Vol.32: pp.2998-2427.

6 Imam, Patrick, 2015, Shock from graying: is the demographic shift weakening monetary policy effectiveness, Int. J. Financ Econ. 20, 138154.

7 Miles, David, 2002, Should monetary policy be different in a Greyer world, In: Alan A., Heinz H. (Eds), “Aging, Financial Markets and Monetary Policy". (Springer, Heidelberg).

8 Mishkin, Fredrik, 1996, The Channels of Monetary Transmission: Lessons for Monetary Policy, NBER Working Paper No. 5464 (Cambridge, MA: National Bureau of Economic Research).

9 Wen-Yi Chen, 2016, Demographic Structure and Monetary Policy Effectiveness: Evidence from Taiwan, Quality and Quantity.

10 Wong, Arlene, 2015, Population Aging and the Transmission of Monetary Policy to Consumption, Working Paper, Northwestern University. 


\section{Apêndice 1}

\section{Tabela 1: Dados utilizados}

\begin{tabular}{l|cccccc|}
\cline { 2 - 6 } PIB & Brasil & Canada & Chile & Estados Unidos & Japão & México \\
\cline { 2 - 6 } & World Data & World Data & World Data & World Data & World Data & World Data \\
Bank & Bank & Bank & Bank & Bank & Bank \\
Taxa de Juros & FCB & FRED & Banco Central & FRED & FRED & Banxico \\
Economic Data & de Chile & Economic Data & Economic Data & \\
& World Data & World Data & World Data & World Data & World Data & World Data \\
Bank & Bank & Bank & Bank & Bank & Bank \\
\hline
\end{tabular}

\section{Apêndice 2}

Funções resposta-impulso da inflação e hiato do produto à mudança de taxa de juros.

\section{Figura 5: Função resposta-impulso: Máxima e Acumulada para o Brasil (1995} até 2016)
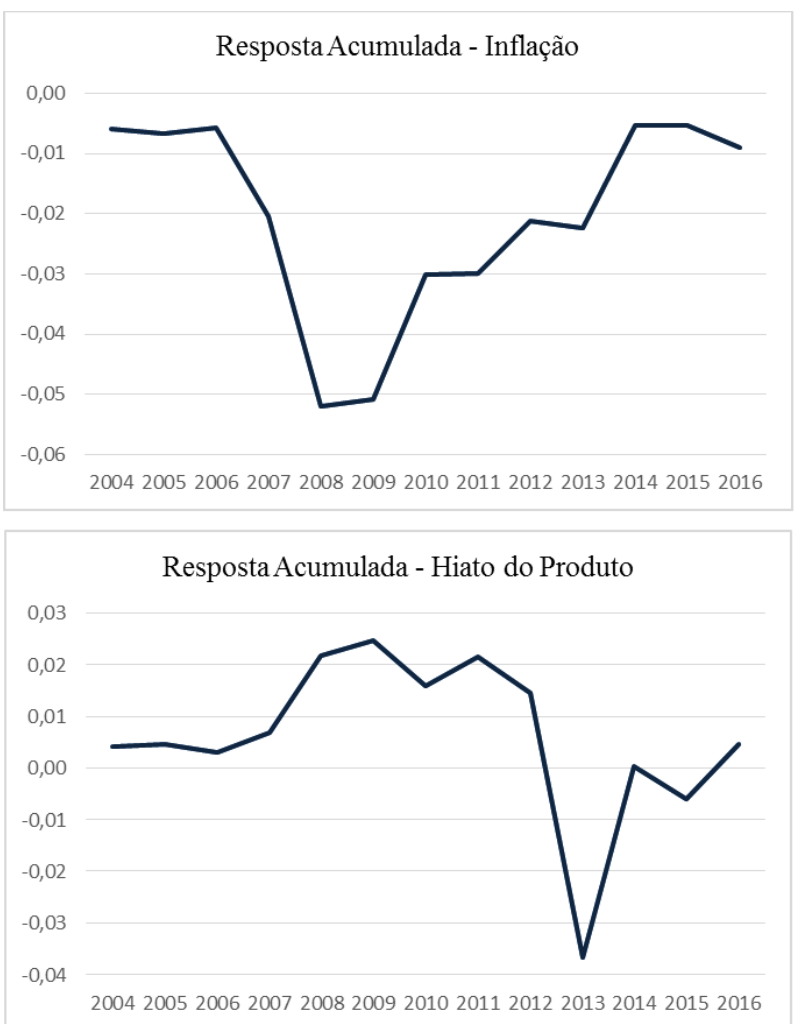
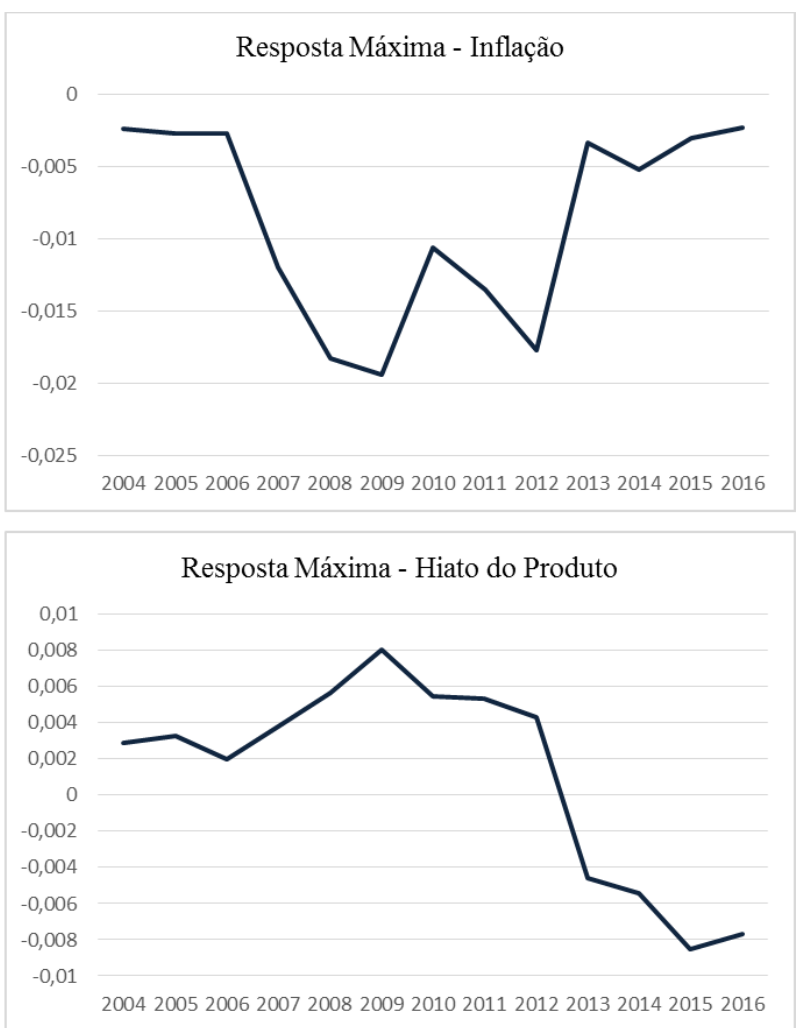
Figura 6: Função resposta-impulso: Máxima e Acumulada para o Canada (1967 até 2016)
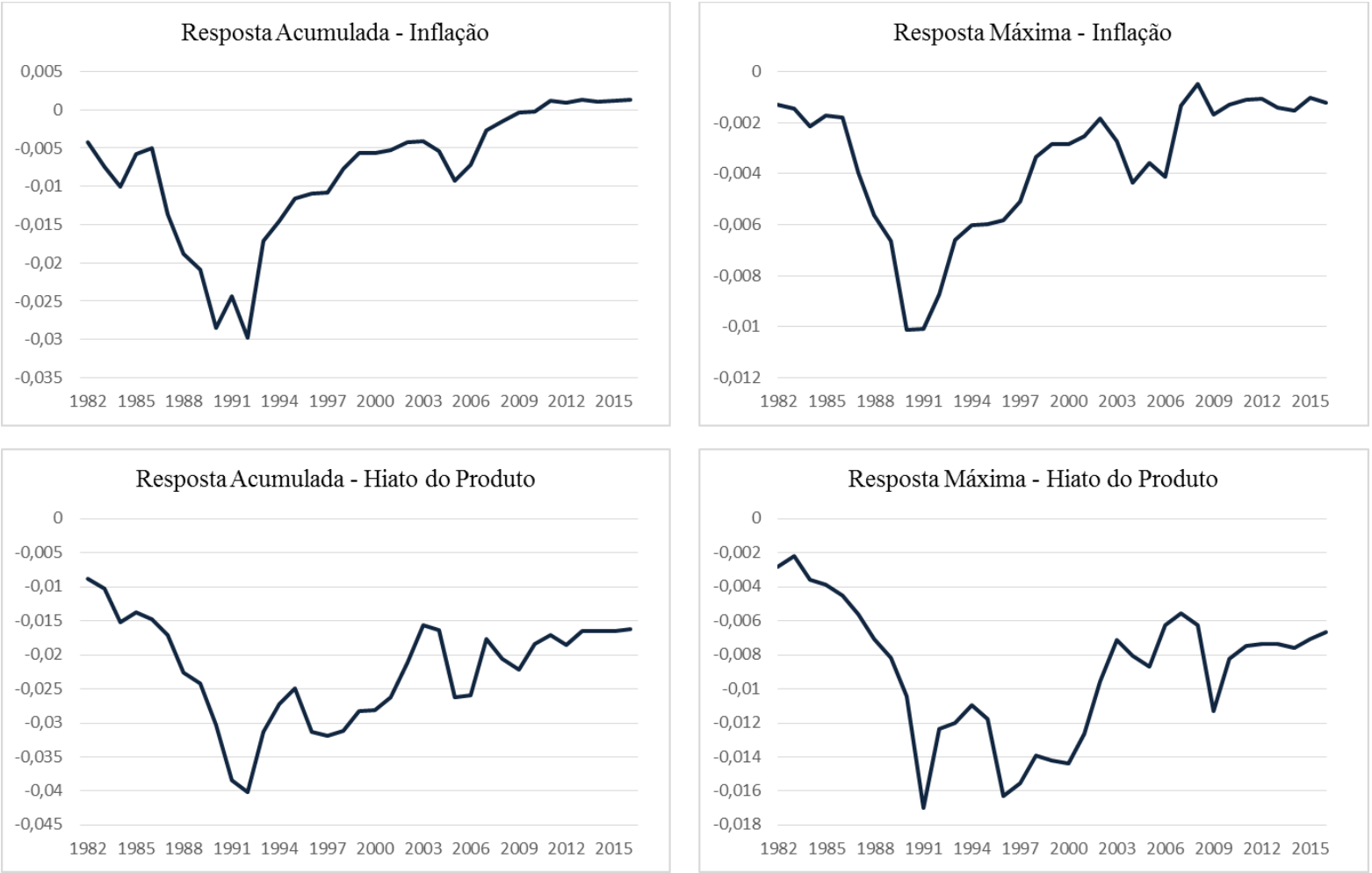

Figura 7: Função resposta-impulso: Máxima e Acumulada para o EUA (1967 até 2016)
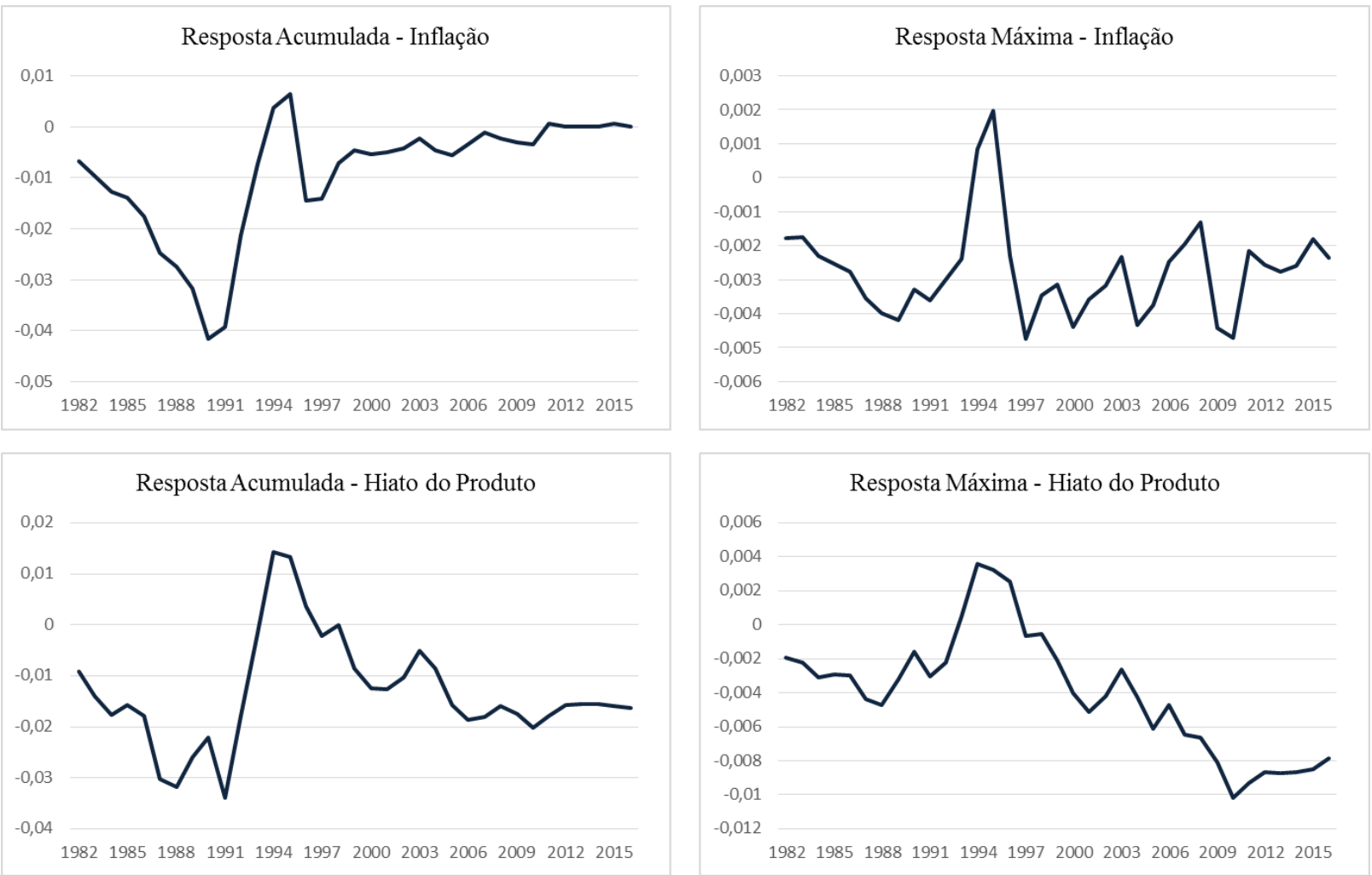
Figura 8: Função resposta-impulso: Máxima e Acumulada para o Japão (1979 até 2016)
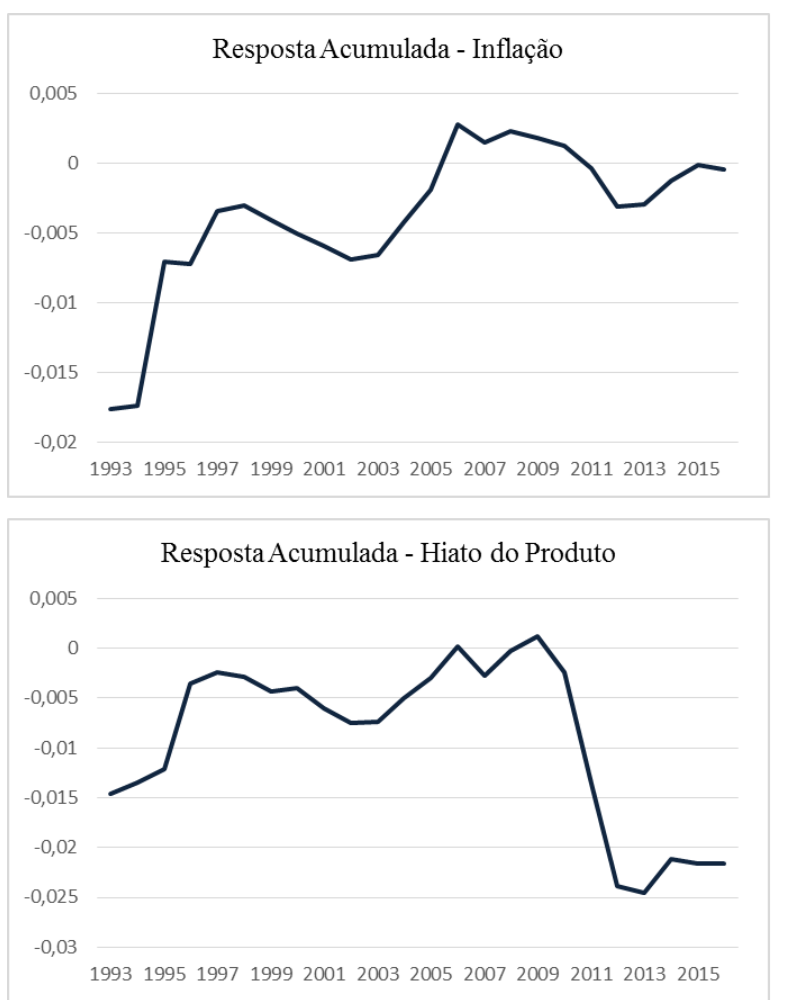
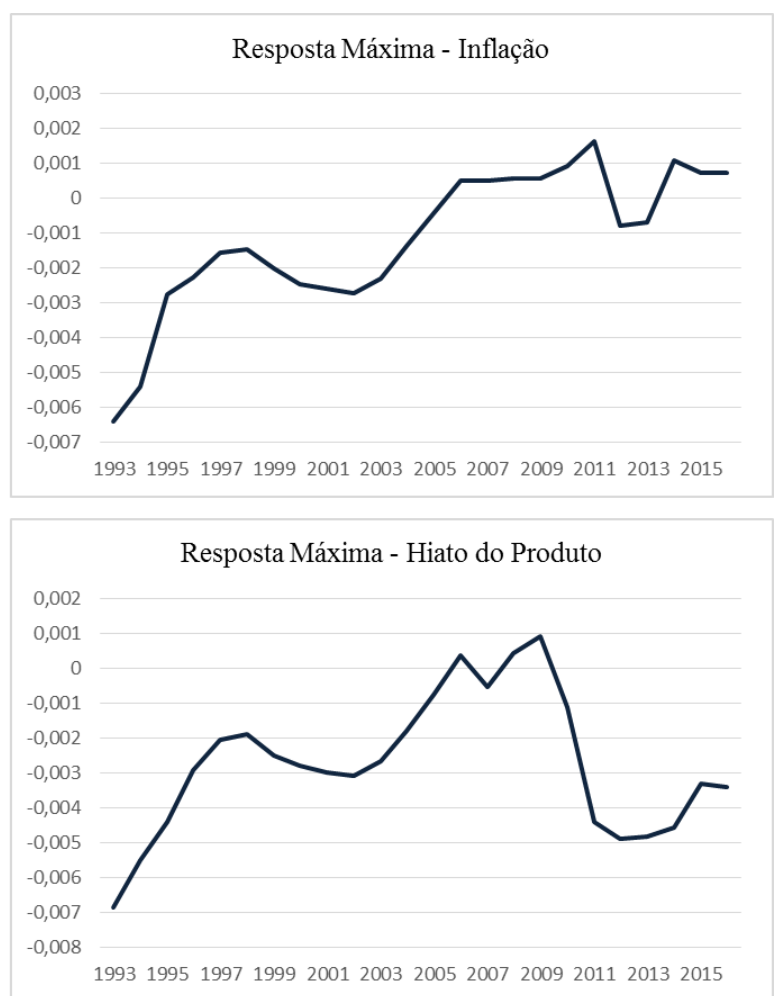

Figura 9: Função resposta-impulso: Máxima e Acumulada para o México (1990 até 2016)
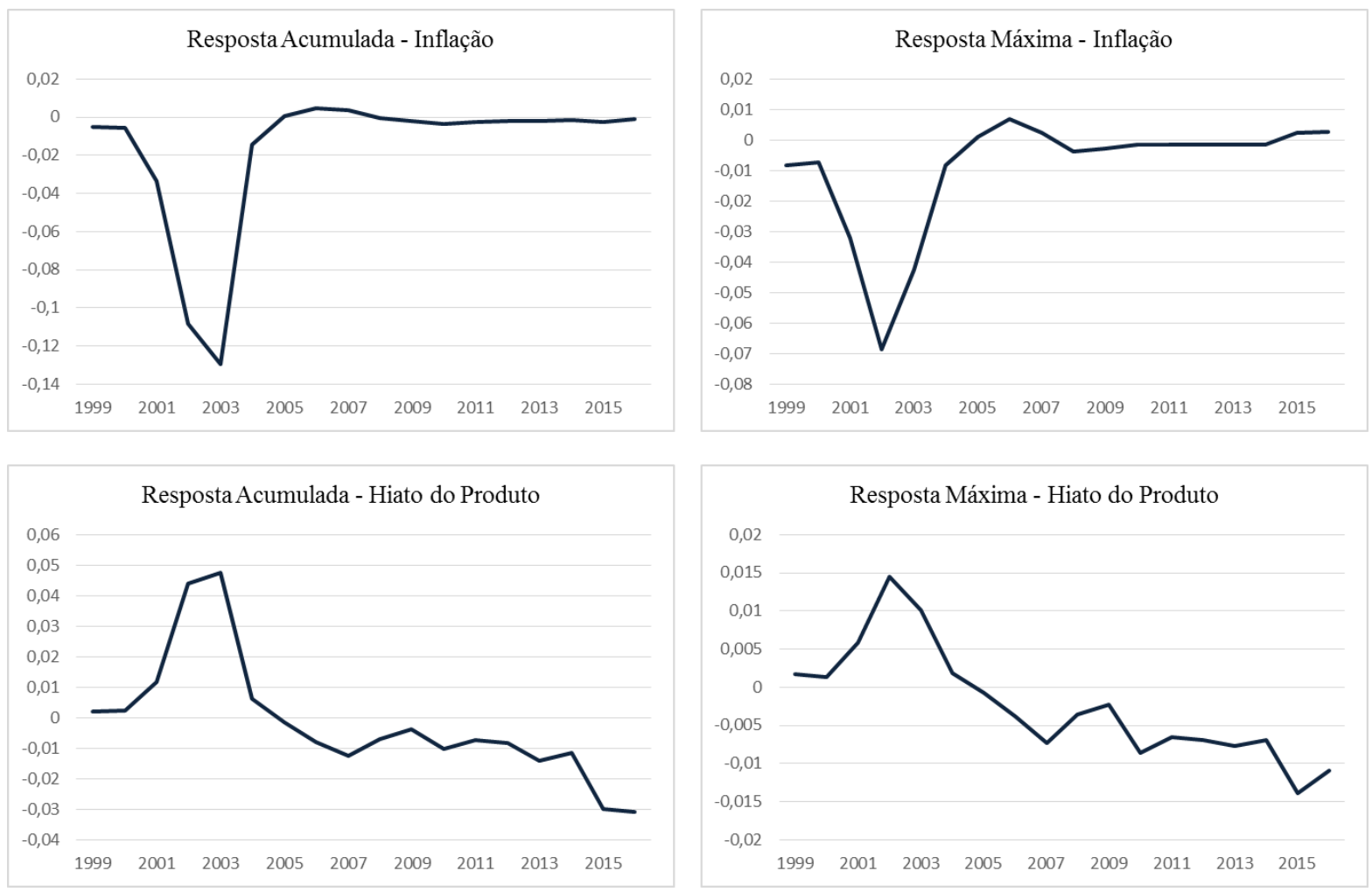
Figura 10: Função resposta-impulso: Máxima e Acumulada para o Chile (1995 até 2016)
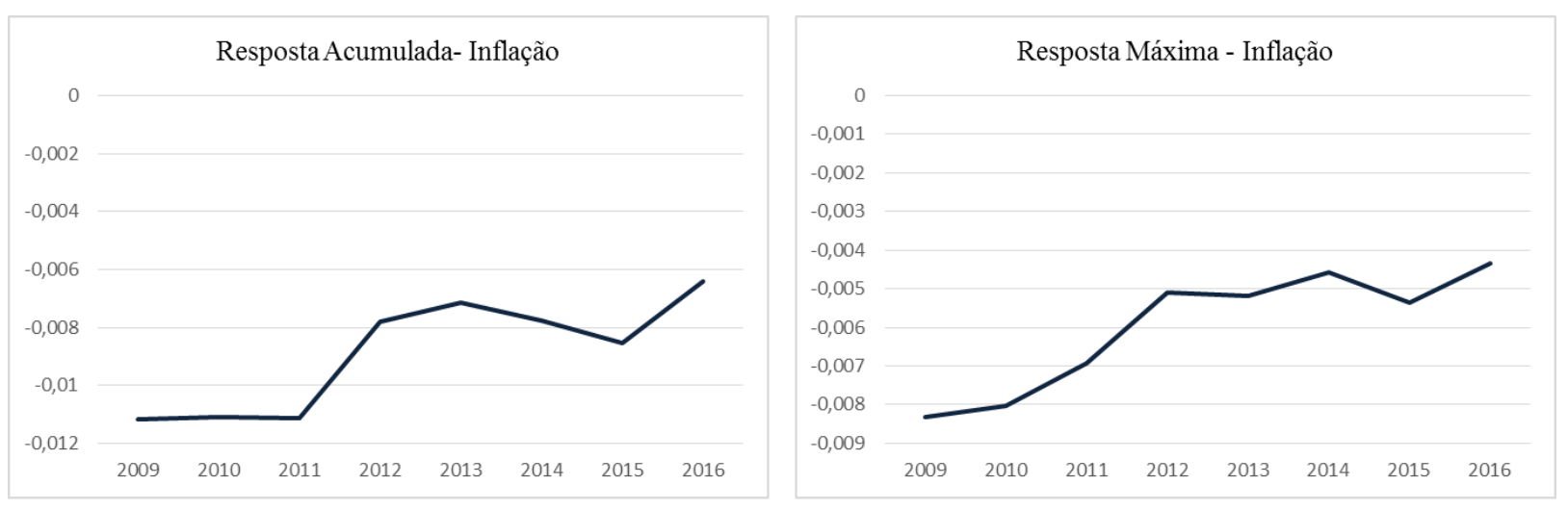

ل)

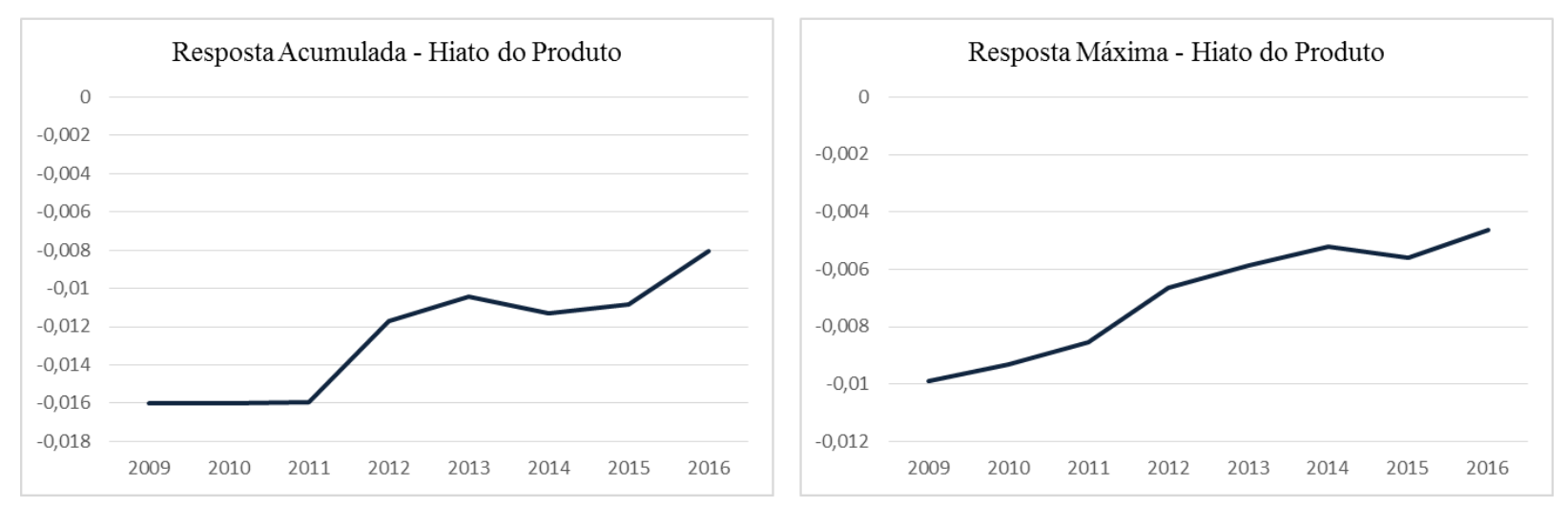

